\title{
El grafismo rupestre paleolítico de la cueva de EI Mirón (Ramales de la Victoria, Cantabria, España): una propuesta para su datación estratigráfica
}

\author{
The Paleolithic rock art of El Mirón (Ramales de la Victoria, Cantabria, Spain): \\ a proposal for its stratigraphic dating
}

\author{
Marcos García Díez (*) \\ Manuel R. González Morales (**) \\ Lawrence G. Straus (**) (***)
}

\begin{abstract}
RESUMEN
Este artículo describe el arte parietal descubierto en la Cueva de El Mirón (Cantabria, España) en el curso de las excavaciones dirigidas en el yacimiento por MGM y LGS desde 1996. El arte consiste en grabados, la mayoría de ellos aparentemente no figurativos en su estado actual, pero hay una imagen de un caballo y otra de un posible bisonte. Todos los grabados se localizan en el fondo del gran vestíbulo, a plena luz, en íntima relación con los depósitos de origen humano. El caballo y los grabados lineales asociados a él en las paredes de la cueva pueden atribuirse al Magdaleniense inferior o medio sobre la base de su estilo y de la altura practicable sobre las superficies de ocupación de estos períodos. Datables con mayor precisión son dos grupos de grabados lineales sobre un gran bloque que pueden asignarse al Magdaleniense inferior cantábrico, un período bien caracterizado por sus obras de arte mueble, como los omóplatos grabados, en El Mirón y en otros varios yacimientos regionales. El bloque cayó de la pared de la cueva, con su cara exterior yaciendo sobre el nivel 110, datado por radiocarbono en $16.130 \pm 250$ y $16.520 \pm 40$ BP. A partir de entonces se grabó su cara originalmente interior. A continuación, el bloque y sus grabados fueron progresivamente recubiertos por sedimentos del Magdaleniense medio, superior y final datados entre ca. 14.50012.000 BP. En suma, el arte descubierto y estudiado
\end{abstract}

(*) Dpto. de Geografía, Prehistoria y Arqueología, Universidad del País Vasco, Tomás y Valiente s/n, 01006 Vitoria-Gasteiz, España. Correo e.: marcos.garcia@ehu.es

(**) Instituto Internacional de Investigaciones Prehistóricas de Cantabria, Edificio Interfacultativo. Avda. de los Castros s/n. 39071 Santander. Cantabria. España. Correo e.: moralesm@unican.es

(***) Dpto. de Antropología. Universidad de New Mexico. Albuquerque, NM 87131. EE.UU. Correo e.: lstraus@unm.edu Recibido: 4-VI-2010; aceptado: 5-X-2010. hasta la fecha en El Mirón puede atribuirse al Magdaleniense inferior y medio, aunque el yacimiento estuvo habitado por los humanos al menos desde el Paleolítico medio hasta época medieval. El artículo concluye situando el arte parietal de El Mirón en el contexto de las otras numerosas (pero peor datadas) manifestaciones de arte rupestre de la cuenca del río Asón, en la Cantabria Oriental, que incluyen sitios tan notables como Venta de la Perra, Covalanas, La Haza y Cullalvera.
ABSTRACT
This article describes the rock art discovered in El Mirón Cave (Cantabria, Spain) during the course of excavations directed by LGS and MGM since 1996. The art consists of engravings: most are apparently non-re- presentational in their currest condition, but there is one image of a horse and another of a possible bison. The engravings are all located at the rear of the large, sunlit vestibule of the cave, in intimate relationship with human habitation deposits. The horse and associated linear en- gravings on the cave wall can be attributed to the early- middle Magdalenian on the basis of style and practicable height above occupation surfaces of those periods. More precisely datable, two series of linear engravings on a large block can be assigned to the Lower Cantabrian Magdalenian, a period well-endowed with works of por- table art, such as engraved scapulae, both at El Mirón and in many other regional sites. The block fell from the cave wall, its outer surface landing on Level 110, which is $14 C$-dated to $16,130 \pm 250$ and 16,520 $\pm 40 \mathrm{BP}$. Then the flat inner surface of the block was engraved. Next, the block and the engravings were progressively covered over by sediments pertaining to Middle, Upper and Ter- minal Magdalenian levels 14C-dated between ca. 14,500- 12,000 BP. In sum, the art discovered to date in El Mirón can be attributed to the early and middle Magdalenian period, although the site itself was inhabited by humans 
from at least late Middle Paleolithic through Medieval times. This article concludes by placing the Mirón parietal art within the context of the numerous other (but less-well dated) cave art manifestations in the river Asón basin of eastern Cantabria, including such notable sites as Venta de la Perra, Covalanas, La Haza and Cullalvera.

Palabras clave: Arte parietal paleolítico; Datación estratigráfica; Paleolítico superior; Magdaleniense; Región Cantábrica.

Key words: Palaeolithic rock art; Stratigraphic dating; Upper Palaeolithic; Magdalenian; Cantabrian Region.

\section{LA CUEVA DE EL MIRÓN: LOCALIZACIÓN, INVESTIGACIÓN Y OCUPACIÓN HUMANA}

La Cueva de El Mirón (también conocida históricamente como Cueva del Francés o Cueva de los Gitanos) se localiza en la ladera oeste del Monte Pando, muy cerca del núcleo de población de Ramales de la Victoria (Cantabria) y a $1 \mathrm{~km}$ del límite con Vizcaya (Fig. 1). Se encuentra a unos 250 m.s.n.m. Sus coordenadas geográficas son $43^{\circ} 14^{\prime} 47.4^{\prime \prime} \mathrm{N}$ y $3^{\circ} 27^{\prime} 4.5^{\prime \prime} \mathrm{O}$ (coordenadas UTM 30T 0463365/4788375).
El Mirón presenta una boca de grandes dimensiones, orientada al Oeste (Fig. 2). El vestíbulo mide entre 8 y $16 \mathrm{~m}$ de ancho, unos $30 \mathrm{~m}$ de fondo y entre 12 y $20 \mathrm{~m}$ de altura. Al final del vestíbulo se encuentra la base de un empinado depósito de limos arenosos y arcillosos y de cantos rodados que se eleva hacia la galería interior de la cueva, un pasadizo de un centenar de metros, relativamente recto, de suelo nivelado y por lo general de unos $8 \mathrm{~m}$ de ancho y unos $3 \mathrm{~m}$ de altura máxima. A juzgar por el contorno y el ángulo de las paredes de la cueva, tanto el vestíbulo como la galería contaban con rellenos sedimentarios muy profundos. Lo confirman las excavaciones en curso (hasta más de $3 \mathrm{~m}$ de profundidad actualmente), los sondeos de georradar (que señalan la roca madre a 9-10 m) y la perforación de un sondeo de $4 \mathrm{~cm}$ de diámetro efectuada en la zona de entrada de la cueva en 2003, que ha permitido muestrear sedimentos hasta $6,75 \mathrm{~m}$ de profundidad a partir de la superficie original del suelo de la cueva. El frente del vestíbulo, al exterior, tiene el característico perfil de equilibrio en forma de arco de medio punto y está sembrado de grandes bloques de derrumbe de la bóveda. Su centro y fondo no han sufrido
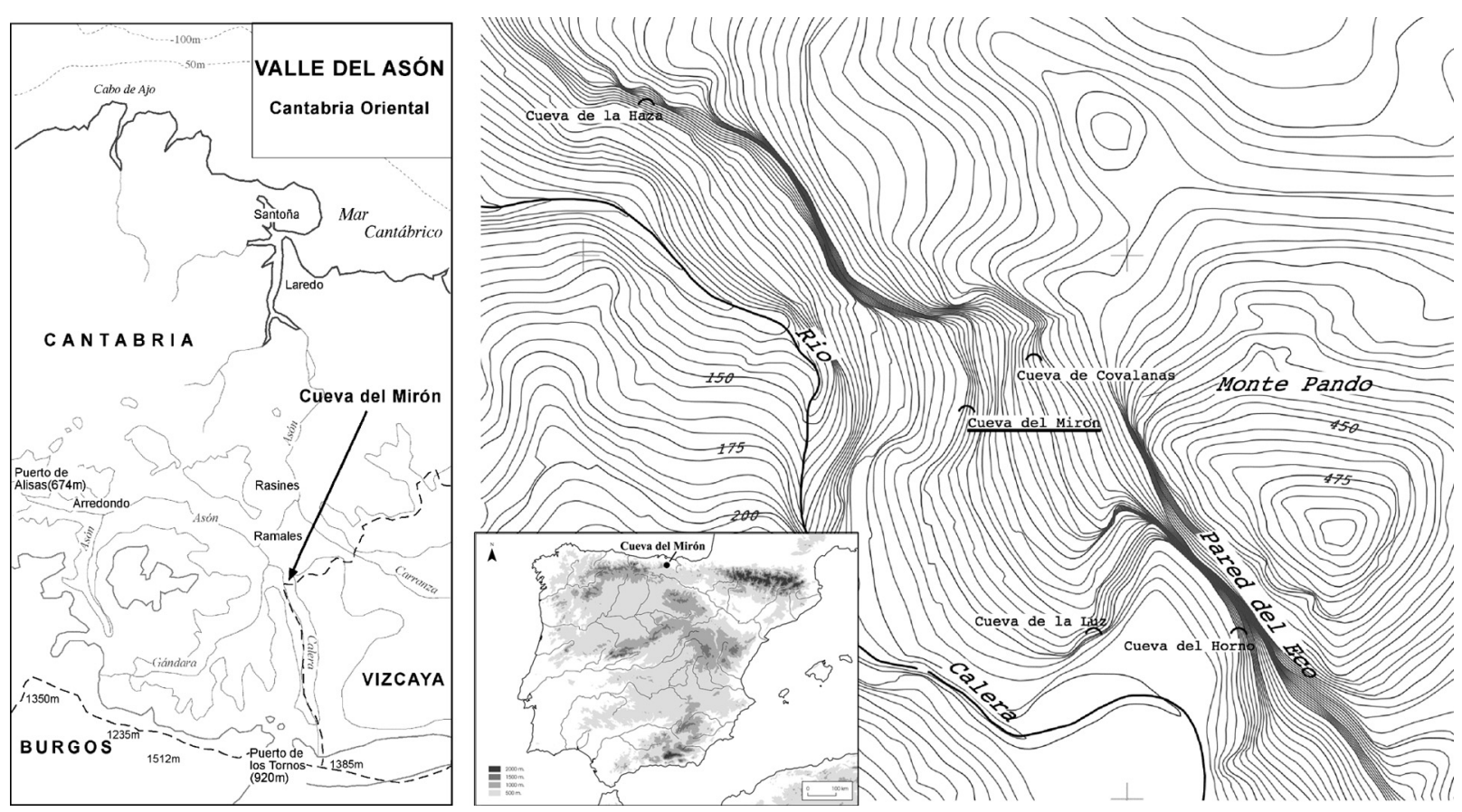

Fig. 1. Localización geográfica de la cueva de El Mirón (Ramales de la Victoria, Cantabria) en la Península Ibérica.

Trab. Prehist., 69, N. ${ }^{\circ}$ 1, enero-junio 2012, pp. 21-36, ISSN: 0082-5638 doi: $10.3989 /$ tp. 2012.12077 


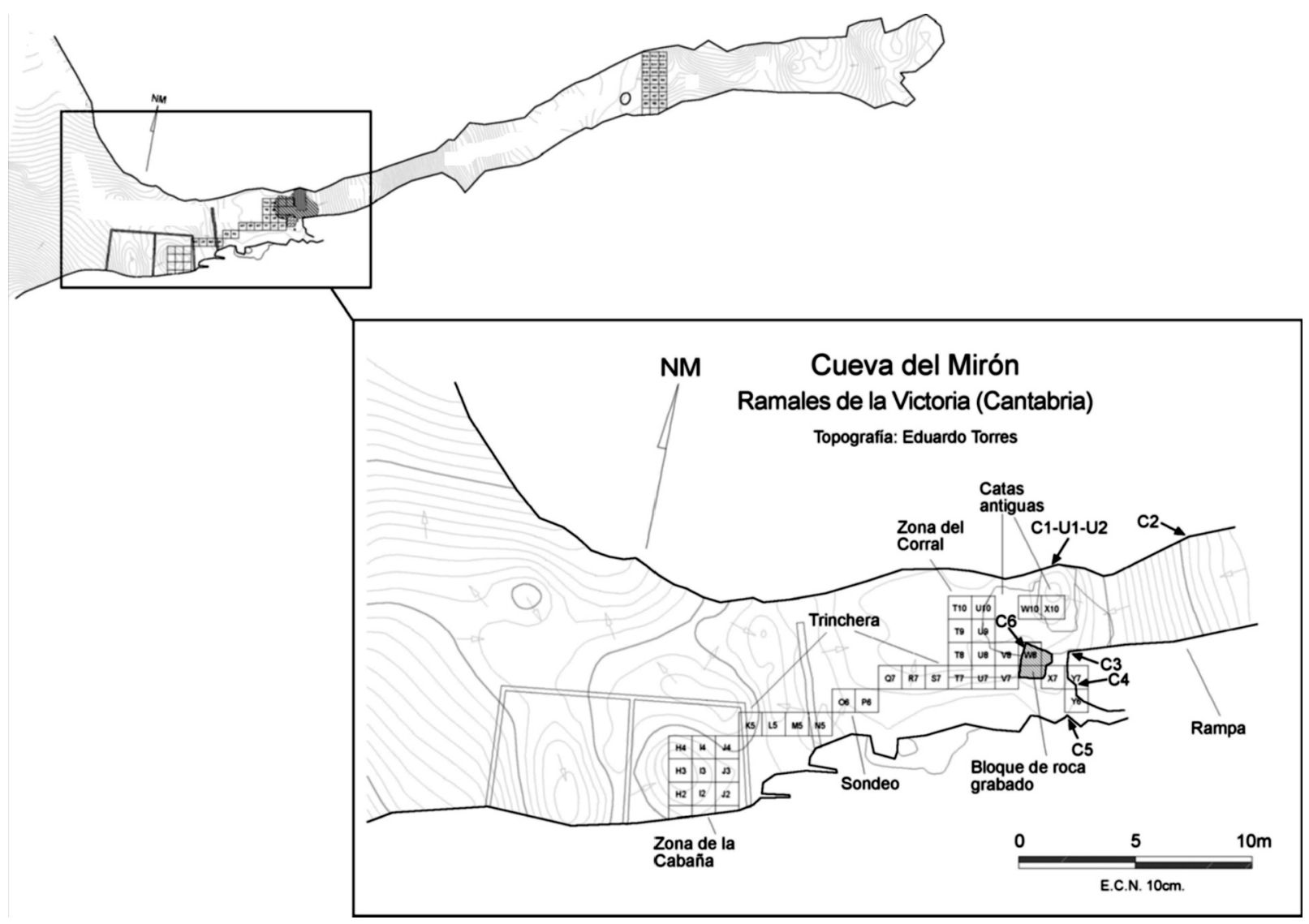

Fig. 2. Plano general y detalle de la entrada de la cueva de El Mirón (Ramales de la Victoria, Cantabria) con la localización de los conjuntos gráficos y unidades gráficas citadas en el texto (levantamiento topográfico de E. Torres Cosío, Speleo Club Cántabro Universitario).

ese proceso. De su techo plano cuelgan algunas escasas estalactitas de gran tamaño y muy alteradas, indicio de la falta de caída de bloques en un período prolongado. El desarrollo total accesible es de unos $130 \mathrm{~m}$.

En torno al Mirón está documentado un importante conjunto de cuevas con arte rupestre paleolítico. Covalanas está a unos $50 \mathrm{~m}$ justamente por encima. En el mismo sector del monte Pando, La Haza se sitúa a unos $60 \mathrm{~m}$ por debajo y unos $400 \mathrm{~m}$ hacia el NO de El Mirón. Cullalvera, también en el municipio de Ramales de la Victoria, se encuentra a $1,2 \mathrm{~km}$ al NNO y a unos $150 \mathrm{~m}$ por debajo de la cota de El Mirón. El valle del río Carranza, con sus numerosas cuevas con arte parietal, se sitúa al NE y al otro lado del macizo del Moro; su confluencia con el río Asón se sitúa a 4 km de Ramales, en Gibaja. El gran yacimiento superomagdaleniense y aziliense de la Cueva del Valle (municipio de Rasines) -conocido por su enorme riqueza en arte mueble- se encuentra a algo más de $2 \mathrm{~km}$ al $\mathrm{NE}$ de la confluencia del Carranza con el río Asón. En las laderas del Monte Pando, cerca de la Cueva de El Mirón, destacan, además, las cuevas de La Luz, con arte paleolítico y yacimiento solutrense, y del Horno, con materiales y dataciones del Magdaleniense superior-final y Aziliense (Straus et al. 2002a, 2002b).

El descubrimiento científico de las cuevas de Covalanas, La Haza y El Mirón en septiembre de 1903 se debió a Hermilio Alcalde del Río y Lorenzo Sierra (Alcalde del Río 1906; Sierra 1909; Alcalde del Río et al. 1911). En aquellos primeros años se documentó en superficie industria lítica de diversos momentos paleolíticos en El Mi- 
rón, y se pensó que la cavidad contenía un depósito arqueológico removido, idea que se mantuvo años después (Cabré 1915; Obermaier 1916). La única 'excavación' antigua (no publicada) cuya autoría se conoce es una trinchera en el interior de la cavidad en los años 1950 debida a los obreros que hicieron el camino de acceso a Covalanas, bajo la dirección del ingeniero $\mathrm{A}$. García Lorenzo.

El proyecto de investigación sobre la Cueva de El Mirón se inició en 1996, con campañas anuales de excavación que continúan hasta el presente. Diversas publicaciones describen los aspectos historiográficos de la cueva (González Morales y Straus 1997) y detallan las distintas zonas de la excavación, su estratigrafía y los principales resultados (González Morales y Straus 2000a, 2000c; Straus y González Morales 1996, 1997, 1998, 1998-99, 1999-2000, 2000, 2001a, 2001b, 2003c; Straus et al. 2001). Aspectos más concretos de la secuencia magdaleniense y sus materiales se analizan en artículos específicos (González Morales y Straus 2005; González Morales et al. 2006; Straus y González Morales 2003a, 2005). La discusión del conjunto de dataciones de radiocarbono también se ha tratado de manera monográfica en tres artículos (Straus y González Morales 2003b, 2008, 2010).

En el vestíbulo se han excavado dos áreas de unos 9-10 $\mathrm{m}^{2}$ conectadas por una trinchera: la 'Cabaña' en la parte anterior y el 'Corral' en el fondo, utilizada hasta fechas recientes como cuadra para ganado ovicaprino. Las paredes están desgastadas por el roce de animales y manchadas por pintadas y humo, y el suelo estaba recubierto por paja y excrementos al iniciarse la excavación.

La secuencia cronoestratigráfica documentada en la 'Cabaña' y en una parte de la trinchera es la siguiente: Magdaleniense inferior, medio y superior (niveles 17-12 y 312-307), Aziliense (niveles 11.2-11 y 306-305), Mesolítico arqueológicamente pobre y con posibles hiatos sedimentarios (niveles 10.1 y 304), Neolítico (niveles 10-8 y 303.3-303), Calcolítico (niveles 7-4 y quizá parte del 302) y Bronce Inicial (niveles 3-2).

Para el presente trabajo interesa de manera especial, por su relación con el grafismo rupestre, la secuencia del 'Corral'. Si se exceptúan algunos materiales de superficie, la secuencia cronocultural post-pleistocénica falta por completo (muy probablemente por la remoción de tierras al nivelar la superficie, aunque no hay evidencias claras en las paredes de la cueva).

La secuencia del 'Corral' se estructura en dos sectores. En el sector NE había una zona removida de unos $15-20 \mathrm{~m}^{2}$, por la actuación de clandestinos. Por debajo se documentaron niveles arqueológicos intactos (se inicia la secuencia con el nivel 120, un estrato limo arcilloso amarillento). En un sondeo de 2,3 $\mathrm{m}$ de profundidad en una superficie de $2 \mathrm{~m}^{2}$ (cuadros W-X10), los niveles arqueológicos han aportado escasos materiales que se atribuyen, por las fechas de $\mathrm{C}^{14}$, al Paleolítico medio terminal y al Paleolítico superior antiguo (niveles 130-128), cubiertos por niveles solutrenses (127-121) datados en torno al 19.000-18.000 BP.

En el sector superior de la secuencia del 'Corral' se ha excavado un área de unos $9 \mathrm{~m}^{2}$ al $\mathrm{S}$ y al $\mathrm{O}$ del pozo antes descrito. Un gran bloque caído de la pared de la cueva y grabado posteriormente es su límite SE. En este sector se han identificado niveles atribuidos al Magdaleniense inicial e inferior-medio (119-108) extremadamente ricos en industria lítica, ósea y en fauna (en especial cabra montés y ciervo, con numerosos restos de salmón). De los hogares y estructuras se dispone de 19 fechas $\mathrm{C}^{14}$ que determinan un lapso entre 17.000-13.700 BP. El nivel 107 está parcialmente alterado por madrigueras fácilmente reconocibles. Los niveles 106-103 son discontinuos y con pocos restos arqueológicos del Magdaleniense superior. El nivel 102.1 es un lentejón de hogar datado en 11.950 BP, Magdaleniense terminal. Los niveles 102-101 son arqueológicamente muy pobres (unas pocas lascas y esquirlas de hueso) y deben corresponder con ocupaciones azilienses o mesolíticas, ya que no se han localizado cerámicas.

El mayor impacto habitacional durante el Paleolítico en la cueva de El Mirón se vincula con momentos del Magdaleniense antiguo sin arpones. Además de documentarse este tipo de ocupaciones en el área de la 'Cabaña' y en el 'Corral', se han registrado en un pequeño sondeo abierto en la parte profunda y oscura de la cueva, en el fondo de la trinchera de A. García Lorenzo, donde industria lítica y fauna se asocian a una fecha de 14.620 BP. La ocupación de la cueva por los humanos durante el Tardiglacial (como en muchas otras cuevas de la Región Cantábrica) fue intensa. 


\section{EL GRAFISMO RUPESTRE DE LA CUEVA DE EL MIRÓN: APUNTES HISTORIOGRÁFICOS, CONSERVACIÓN E IMPLICACIONES EN EL ESTUDIO Y DESCRIPCIÓN DEL DISPOSITIVO ICONOGRÁFICO}

El grafismo rupestre de la cueva de El Mirón no ha sido estudiado hasta fechas recientes. Por la descripción de H. Alcalde del Río (1906: 46), sabemos que en los primeros años del siglo XX revisaron las paredes en busca de manifestaciones: "En toda ella sus paredes carecen del más pequeño vestigio de gráfica".

Dentro del proyecto de excavación y estudio de la cueva de El Mirón, uno de nosotros (MGM) identificó al inicio de las excavaciones en 1996 las primeras evidencias gráficas sobre un bloque que se encuentra parcialmente cubierto por niveles arqueológicos intactos y que ha sido objeto de varias referencias (Straus y González Morales 1996: 16, 1998: 176, 1998-99: 5, 2000: 355; González Morales y Straus 2000a: 126) y de una publicación preliminar algo más extensa (González Morales y Straus 2000b). La posterior localización en la pared izquierda de grabados incisos muy finos ha sido objeto de escuetas alusiones dentro de valoraciones generales del yacimiento (González Morales y Straus 2000a: 126; Straus y González Morales 2003c).

Con posterioridad a la elaboración de este artículo se ha podido localizar una nueva zona con múltiples grabados muy finos sobre una superficie reducida, inmediata al conjunto 1 y que estuvo recubierta por el sedimento. Las dificultades para poder trabajar en la cueva, por motivos administrativos, durante los años 2008 y 2009 ha impedido poder completar el estudio de estas representaciones, que posponemos para otra futura publicación.

El dispositivo iconográfico de la cueva de El Mirón se ve afectado por una acción física que debe su génesis a alteraciones químicas del soporte y a la exposición de éste a la dinámica ombrotérmica exterior. Las superficies externas de las paredes de la cueva muestran dos pátinas bien diferenciadas: una de color grisáceo propio de la caliza (en diferentes tonalidades) y otra marrón-rojiza. La segunda testimonia procesos de alteración de la roca que originan una muy fina capa con alta concentración de hierro (de ahí su color) cuya delgadez y bajo grado de cohesión con el soporte representa una zona de debilidad manifestada por desconchados.

Hemos organizado y descrito las grafías de acuerdo a unidades y conjuntos gráficos. La unidad gráfica integra representaciones consideradas conceptos gráficos individuales y con un sentido gráfico preciso. Bajo el término de conjunto gráfico describimos diferentes formas o tipos de representaciones que, por su relación espacial con otras, no pudimos delimitar con unas mínimas garantías. Es decir, es posible que aquello que integramos bajo el concepto de conjunto gráfico pudiera hacer referencia a una o más unidades gráficas en su concepción gráfica original.

Es característica común (tanto de las unidades gráficas como de los conjuntos, a excepción del 4,5 y 6) que los grabados conservados se relacionen con superficies de color marrón-rojizo, grabadas cuando ya se había formado dicha capa. La alteración y la caída de ésta origina la pérdida total o parcial de los trazos. Teniendo en cuenta la anterior consideración y el hecho de que un gran número de líneas grabadas de los diferentes conjuntos $(1,2$ y 3$)$ y unidades (especialmente la 1) se relacionan con uno o varios desconchados, es de suponer la existencia de otros motivos naturales, lineales o geométricos que hoy en día no se conservan o no se han llegado a discriminar.

Los trabajos arqueológicos hasta la campaña de 2007 han puesto de manifiesto las representaciones gráficas que localizamos y describimos a continuación. La tabla 1 resume las características del soporte y los caracteres técnicos de los grabados.

Conjunto gráfico 1 . Se sitúa en la pared izquierda en sentido de entrada (Norte), aproximadamente a $23 \mathrm{~m}$ de la entrada, al fondo del vestíbulo. Se compone de un amplio número de trazos preferentemente rectilíneos que en algunos casos se cruzan creando ángulos (Fig. 3). La disposición de los surcos es variable: horizontal, vertical y oblicua. La longitud de los trazos también lo es: de 0,3 a $4,6 \mathrm{~cm}$. El conjunto se distribuye por una superficie máxima de $220 \mathrm{~cm}$ de ancho y $52 \mathrm{~cm}$ de alto. Su estado de conservación es deficiente debido a la alteración del soporte y a los desconchados de la capa superficial, que afectan a la integridad de los grabados. Sobre el mismo soporte existen gran número de pequeñas grietas o fisuras que pudieran confundirse con trazos antrópicos.

Unidad gráfica 1: se localiza en la pared izquierda, en el mismo panel que el conjunto 1 y en 


\begin{tabular}{|c|c|c|c|c|c|c|c|c|}
\hline \multirow{2}{*}{$\begin{array}{c}\text { CONJUNTO } \\
\text { GRÁFICO / } \\
\text { UNIDAD } \\
\text { GRÁFICA }\end{array}$} & \multicolumn{2}{|c|}{ SOPORTE } & \multicolumn{6}{|c|}{ REPRESENTACIONES } \\
\hline & $\begin{array}{l}\text { Dispo- } \\
\text { sición }\end{array}$ & Morfología & $\begin{array}{l}\text { Técnica de } \\
\text { ejecución }\end{array}$ & $\begin{array}{l}\text { Modo de } \\
\text { ejecución }\end{array}$ & $\begin{array}{c}\text { Morfología } \\
\text { del surco }\end{array}$ & Anchura & Contornos & Profundidad \\
\hline $\begin{array}{l}\text { Conjunto } \\
\text { gráfico } 1\end{array}$ & Subvertical & Cóncava & Grabado & $\begin{array}{c}\text { Incisión con } \\
\text { instrumento } \\
\text { lítico }\end{array}$ & $\begin{array}{c}\text { "V" } \\
\text { simétrica }\end{array}$ & $\geq 0,5 \mathrm{~mm}$ & Regulares & Superficiales \\
\hline $\begin{array}{l}\text { Unidad } \\
\text { gráfica } 1\end{array}$ & Subvertical & $\begin{array}{c}\text { Plana, con } \\
\text { ligero resalte } \\
\text { oblicuo }\end{array}$ & Grabado & $\begin{array}{c}\text { Incisión con } \\
\text { instrumento } \\
\text { lítico } \\
\end{array}$ & $\begin{array}{c}\text { "V" } \\
\text { simétrica }\end{array}$ & $0,5 \mathrm{~mm}$ & Regulares & Superficiales \\
\hline $\begin{array}{c}\text { Unidad } \\
\text { gráfica } 2\end{array}$ & Subvertical & $\begin{array}{c}\text { Plana, con } \\
\text { ligero resalte } \\
\text { oblicuo }\end{array}$ & Grabado & $\begin{array}{c}\text { Incisión con } \\
\text { instrumento } \\
\text { lítico } \\
\end{array}$ & $\begin{array}{c}\text { "V" } \\
\text { simétrica }\end{array}$ & $0,5 \mathrm{~mm}$ & Regulares & Superficiales \\
\hline $\begin{array}{l}\text { Conjunto } \\
\text { gráfico } 2\end{array}$ & Subvertical & Plana & Grabado & $\begin{array}{c}\text { Incisión con } \\
\text { instrumento } \\
\text { lítico } \\
\end{array}$ & $\begin{array}{c}\text { "V" } \\
\text { tendencia } \\
\text { simétrica }\end{array}$ & $0,5 \mathrm{~mm}$ & Regulares & Superficiales \\
\hline $\begin{array}{l}\text { Conjunto } \\
\text { gráfico } 3\end{array}$ & Subvertical & Sinuosa & Grabado & $\begin{array}{c}\text { Incisión con } \\
\text { instrumento } \\
\text { lítico }\end{array}$ & $\begin{array}{c}\text { "V" } \\
\text { tendencia } \\
\text { simétrica }\end{array}$ & $\begin{array}{l}\text { Variable } \\
\text { entre } 0,5 \\
\text { y } 1 \mathrm{~mm} \\
\end{array}$ & Regulares & Superficiales \\
\hline $\begin{array}{l}\text { Conjunto } \\
\text { gráfico } 4\end{array}$ & Subvertical & Sinuosa & Grabado & $\begin{array}{c}\text { Incisión con } \\
\text { instrumento } \\
\text { lítico } \\
\end{array}$ & - & Ancho & - & - \\
\hline $\begin{array}{l}\text { Conjunto } \\
\text { gráfico } 5\end{array}$ & Subvertical & Sinuosa & Grabado & $\begin{array}{l}\text { Incisión con } \\
\text { instrumento } \\
\text { lítico } \\
\end{array}$ & - & - & - & - \\
\hline $\begin{array}{l}\text { Conjunto } \\
\text { gráfico } 6\end{array}$ & $\begin{array}{l}\text { Oblicua } \\
\text { (Bloque } \\
\text { calizo) }\end{array}$ & Plana & Grabado & $\begin{array}{c}\text { Incisión con } \\
\text { instrumento } \\
\text { lítico }\end{array}$ & $\begin{array}{c}\text { "V" } \\
\text { tendencia } \\
\text { simétrica }\end{array}$ & $\begin{array}{l}\text { Variable } \\
\text { entre } 1,5 \\
\text { y } 5 \mathrm{~mm}\end{array}$ & Regulares & $\begin{array}{l}\text { Profundos } \\
\text { o muy } \\
\text { profundos }\end{array}$ \\
\hline
\end{tabular}

Tab. 1. Descripción de los grabados paleolíticos de la Cueva de El Mirón (Ramales de la Victoria, Cantabria).

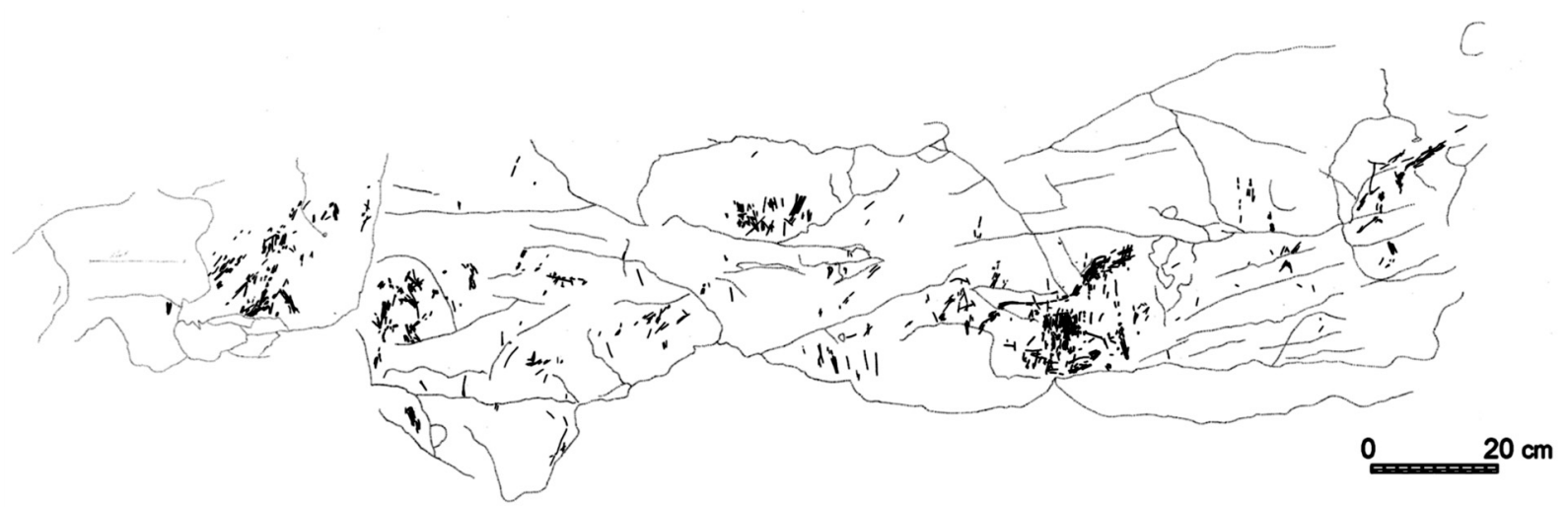

Fig. 3. Conjunto gráfico 1 y unidades gráficas 1 y 2 de El Mirón (Ramales de la Victoria, Cantabria).

relación física con algunos de los trazos anteriormente descritos. Se sitúa a unos $23,5 \mathrm{~m}$ del límite de la boca de entrada. De una representación naturalista zoomorfa de equino (Figs. 3 y 4) se reconoce la línea frontal, las dos orejas, el cuello, la crin, la línea cérvico-dorsal, la extremidad caudal, dos tercios del recorrido del vientre, las dos extremidades delanteras (una parcialmente) y el pecho. Algunos desconchados y fisuras en la zona de la cabeza pudieran sugerir la línea maxilar y la frontal en su integridad. Dado que los desconchados son posteriores a la ejecución del grabado, no consideramos pertinente mantener que formen parte de la composición, a modo de elemento natural con contenido formal. La discriminación de las líneas exactas que componen la figura es 


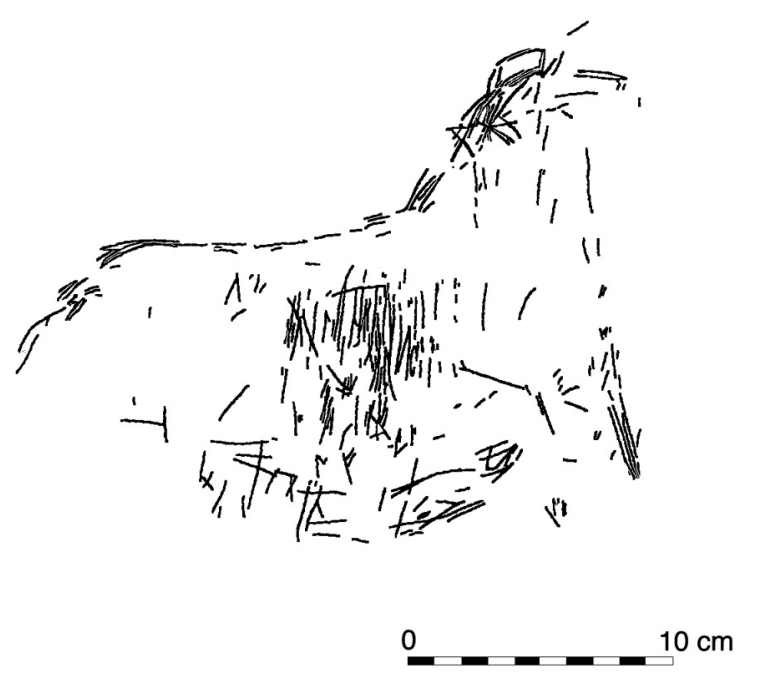

Fig. 4. Unidad gráfica 1 de El Mirón (Ramales de la Victoria, Cantabria): caballo.

difícil. El criterio para individualizar el contorno fue considerar todos los surcos con desarrollo similar al de las diferentes regiones anatómicas. Mayor problema presenta identificar líneas en el interior del cuerpo del animal. Como las líneas que integran el conjunto gráfico 1 componen, preferentemente, pequeños grupos y alrededor del equino no son tan profusas, juzgamos que las situadas en su interior tienen relación directa con él. Además de las líneas de contorno, las situadas en la zona abdominal suelen describir un recorrido paralelo al vientre, y en la región costal, y disponerse claramente en vertical. Su localización, dispersión y disposición describirían, de manera esquemática, el pelaje o el abultamiento que presentan los animales en ese tramo corporal. La figura se orienta hacia el interior de la cavidad y muestra nivelación de $5^{\circ}-15^{\circ}$ derecha. García Díez y Eguizábal (2003: 39, n. 7) presentan las medidas utilizadas en el estudio de los zoomorfos: longitud del cuello $=7 \mathrm{~cm}$; longitud del cuello al gaznate $=6,3 \mathrm{~cm}$; longitud del tronco $=22 \mathrm{~cm}$; distancia de la grupa a la nalga $=4 \mathrm{~cm}$; longitud de las orejas $=0,8 \mathrm{~cm}$; altura de la cruz $=11,6 \mathrm{~cm}$; altura del pecho $=9,4 \mathrm{~cm}$; altura o hueco sub-esternal $=1,2 \mathrm{~cm}$ y anchura máxima $=24 \mathrm{~cm} . \mathrm{El}$ deficiente estado de conservación por la alteración del soporte y por el desconchado, juntamente con el carácter muy estrecho de los surcos impiden reconocer superposiciones. Se asocian al grabado pequeñas fisuras y grietas.

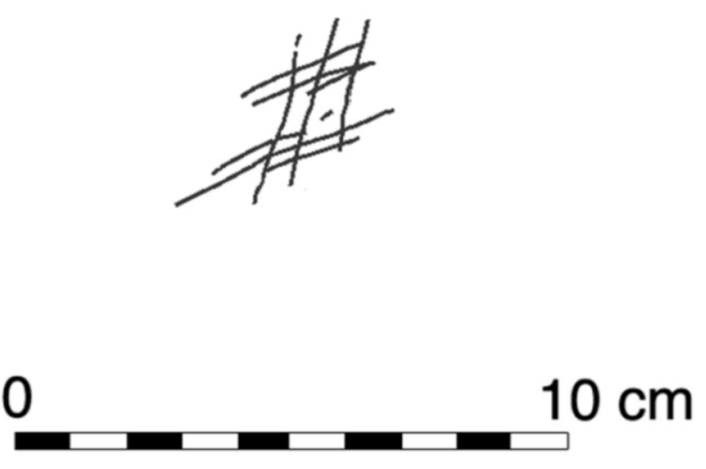

Fig. 5. Unidad gráfica 2 de El Mirón (Ramales de la Victoria, Cantabria): signo reticulado.

Unidad gráfica 2: se asocia a la parte superior de la cabeza de la unidad anterior. Representación de líneas paralelas horizontales y otras paralelas verticales que se cruzan casi ortogonalmente, componiendo un morfotipo reticulado (Fig. 5). Las medidas máximas son 4,4 $\mathrm{cm}$ de ancho y 3,4 $\mathrm{cm}$ de alto. Su estado de conservación es deficiente debido a la alteración del soporte y a los desconchados de la capa superficial, que afectan a la integridad de los grabados.

Conjunto gráfico 2: está en la pared izquierda, a $33 \mathrm{~m}$ de la entrada. El conjunto se compone de un gran número de trazos preferentemente rectilíneos que en ocasiones se cruzan creando ángulos (Fig. 6). La disposición de los surcos es variable: horizontal, vertical y oblicua; su longitud también lo es: de 0,4 a $5 \mathrm{~cm}$. El conjunto se distribuye por una superficie máxima de $86 \mathrm{~cm}$ de ancho y $38 \mathrm{~cm}$ de alto. Su estado de conservación es deficiente debido a la alteración del soporte y a los desconchados de la capa superficial, que afectan a la totalidad e integridad de los grabados. El gran número de pequeñas grietas o fisuras sobre el soporte pudieran confundirse con algún trazo antrópico.

Conjunto gráfico 3: se localiza en la pared derecha (Sur), aproximadamente a $23 \mathrm{~m}$ de la entrada. Se compone de gran número de líneas preferentemente rectilíneas que en ocasiones se cruzan formando ángulos (Fig. 7). La disposición de los surcos es variable: horizontal, vertical y oblicua. $\mathrm{Su}$ longitud también lo es: de 0,2 a $9 \mathrm{~cm}$. Ocupa una superficie máxima de $45 \mathrm{~cm}$ de ancho y 21 $\mathrm{cm}$ de alto. Este conjunto gráfico, en complemen- 


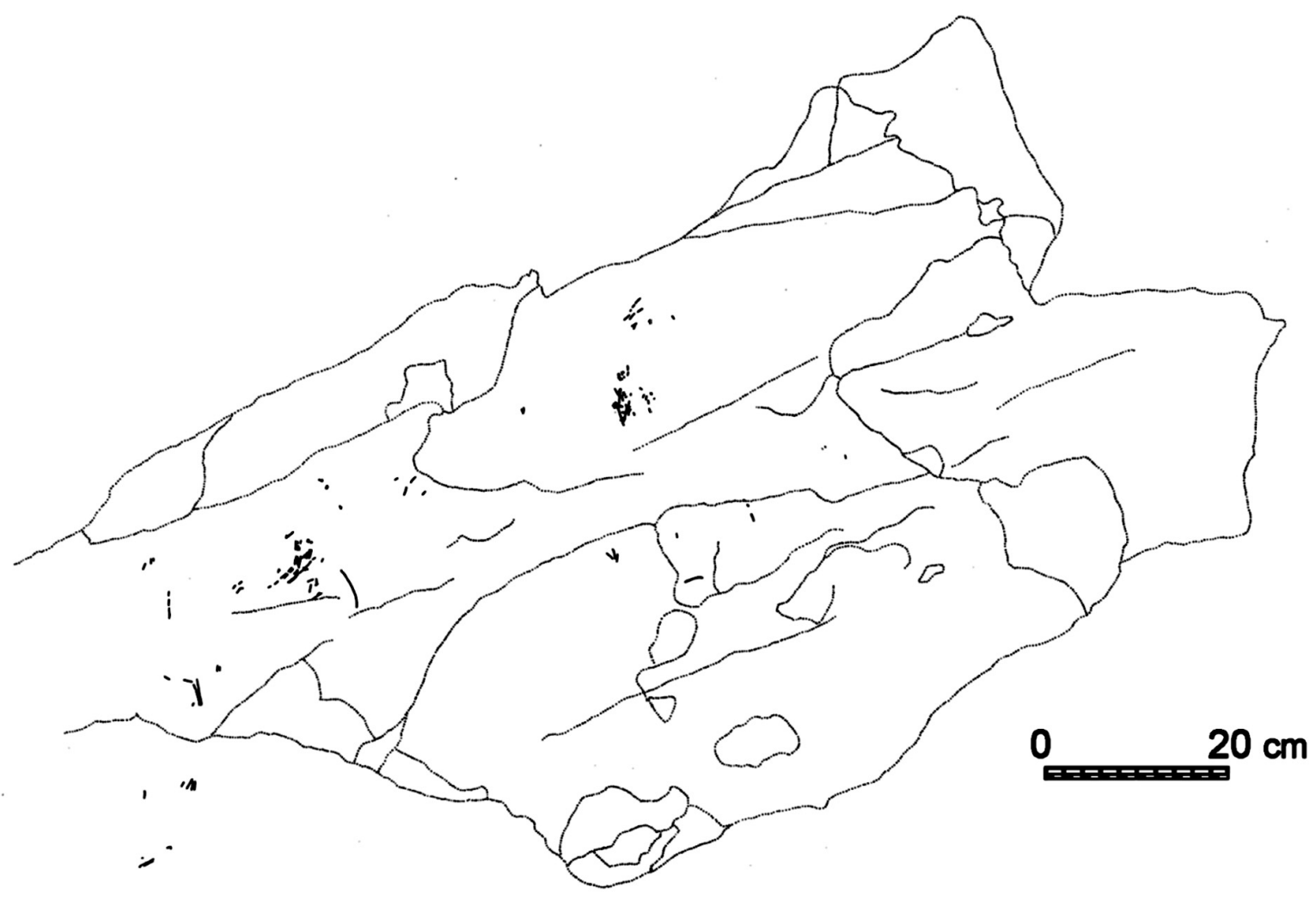

Fig. 6. Conjunto gráfico 2 de El Mirón (Ramales de la Victoria, Cantabria).

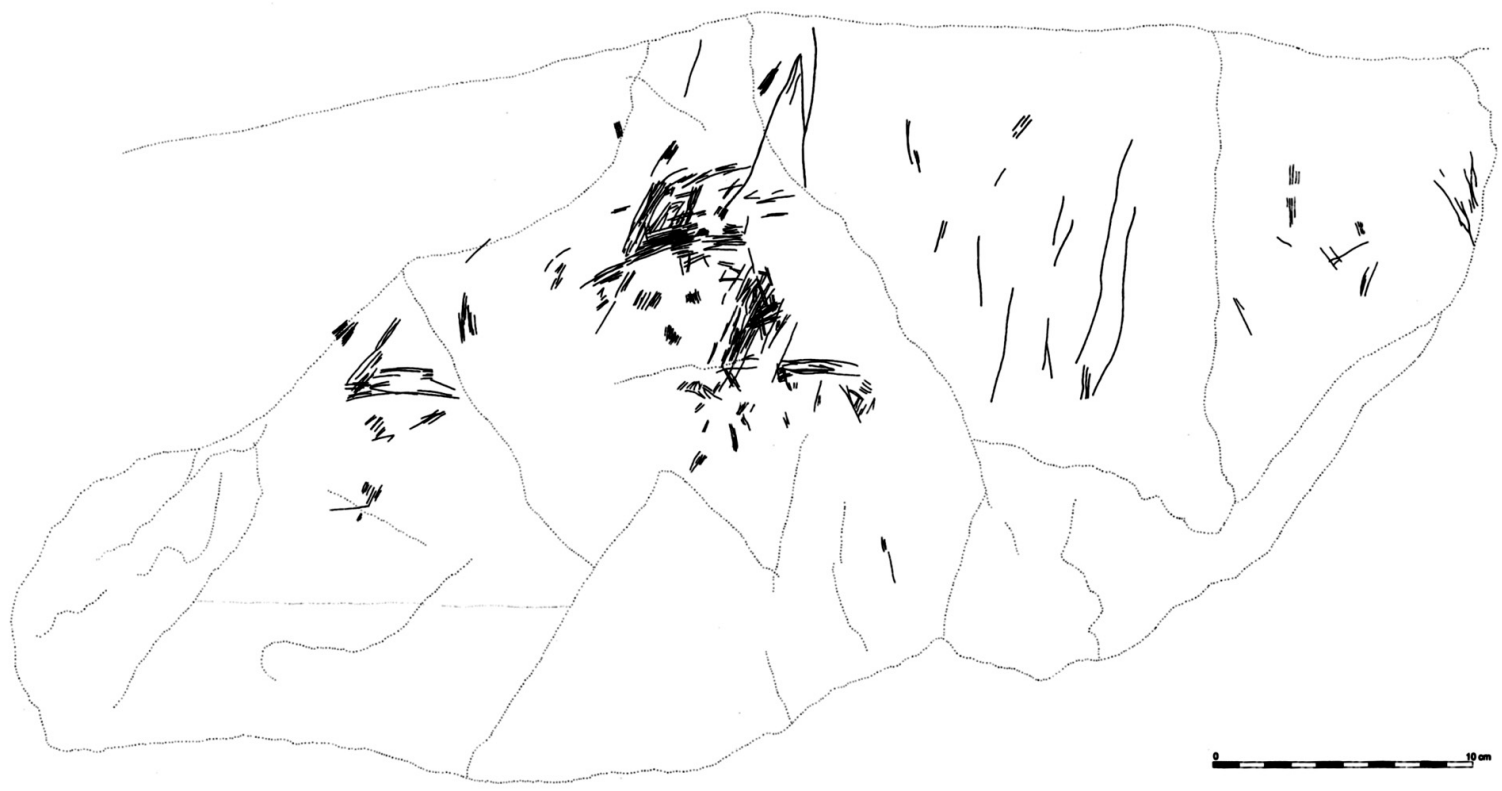

Fig. 7. Conjunto gráfico 3 de El Mirón (Ramales de la Victoria, Cantabria).

Trab. Prehist., 69, N. ${ }^{\circ}$ 1, enero-junio 2012, pp. 21-36, ISSN: 0082-5638 doi: $10.3989 /$ tp.2012.12077 
tariedad con la morfología natural del soporte, pudiera componer una figura tipo bisonte casi completa. La modulación natural de la superficie de la roca y algunas líneas de fractura formarían la estructura general de la línea cérvico-dorsal, grupa, nalga, extremidades (al menos un par), la línea frontal, el ojo y un cuerno. El estado de conservación es deficiente por la alteración del soporte y los desconchados de la capa superficial, que afectan a la integridad de los grabados.

Conjunto gráfico 4: está en la pared del fondo (Este), aproximadamente a $23 \mathrm{~m}$ de la entrada. En la actualidad es imposible una descripción mínimamente detallada de los grabados, ya que parecen continuar bajo los sedimentos arqueológicos. Habrá que esperar a la futura excavación del sector para una caracterización definitiva. A tenor de lo que puede reconocerse, el conjunto se compone de representaciones preferentemente rectilíneas. La disposición de los surcos es generalmente vertical. Su estado de conservación es deficiente por la alteración del soporte.

Conjunto gráfico 5: se localiza en la pared derecha (Sur), a unos $25 \mathrm{~m}$ de la entrada, más concretamente en un pequeño entrante que describe la cavidad. Se compone de un gran número de representaciones preferentemente rectilíneas. Los surcos suelen disponerse en vertical. Los procesos de descalcificación del soporte han alterado su superficie, siendo imposible precisar más allá de indicar que es un tipo de surco ancho.

Conjunto gráfico 6: se localiza en los cuadros W7, W8, X7 y X8 del 'Corral', a unos $21 \mathrm{~m}$ del límite de la entrada. El soporte es un bloque calizo desprendido de la pared que se apoya sobre sedimento arqueológico. La cara decorada es plana, con un fino depósito de color marrón-rojizo que responde a un proceso de alteración por oxidación de la superficie. Se corresponde con la superficie fracturada del bloque en su posición original. Su morfología coincide con un plano de fractura situado por encima de la localización actual del bloque. Las huellas de corriente de la cara inferior, resultantes de procesos erosivos de la superficie externa de la caliza, corroboran que la cara interior es la grabada. El conjunto se compone de un gran número de líneas rectas que en ocasiones se cruzan formando ángulos (Fig. 8). La

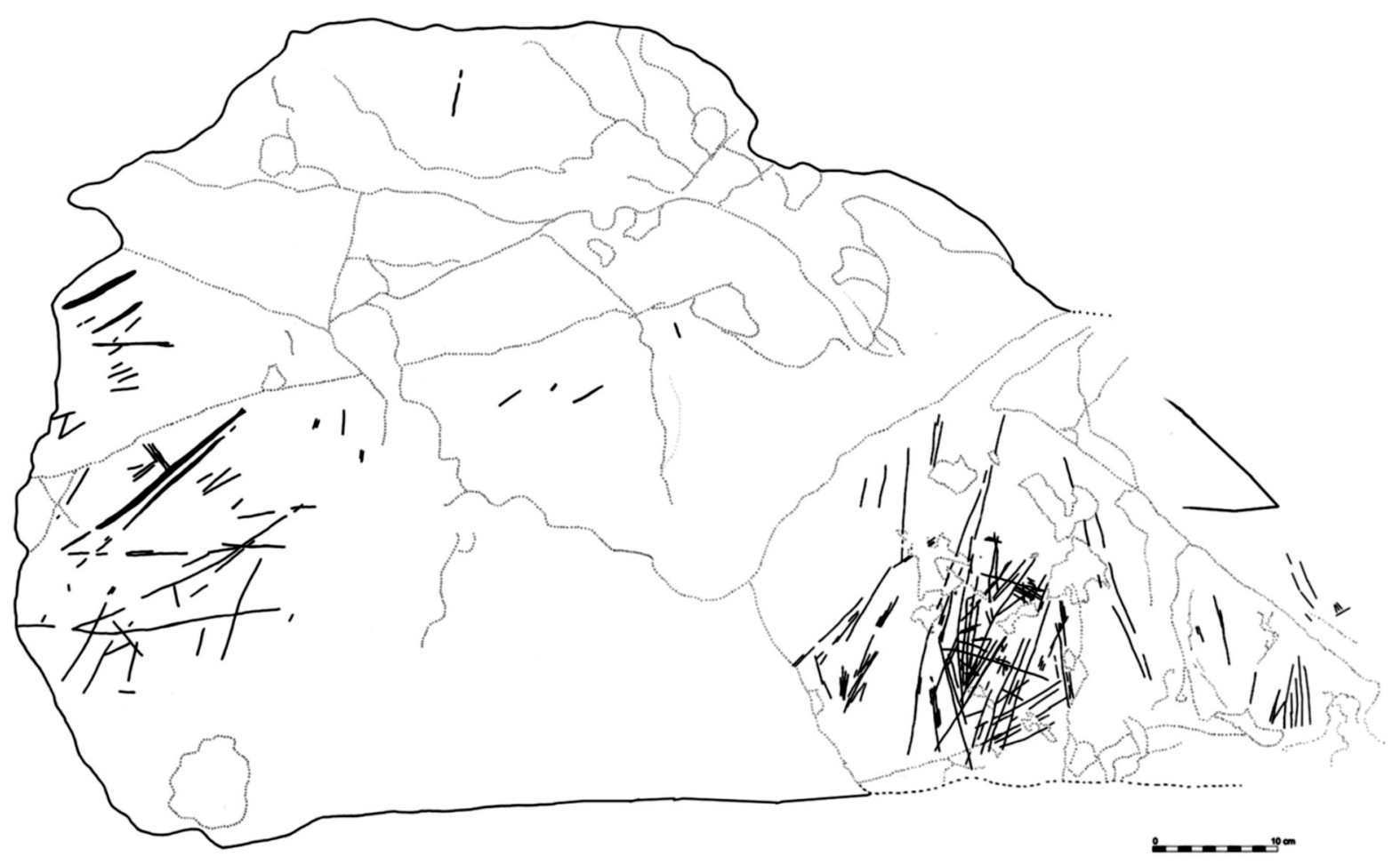

Fig. 8. Conjunto gráfico 6 de El Mirón (Ramales de la Victoria, Cantabria), correspondiente a la superficie del gran bloque desprendido. 
disposición de los surcos es variable: horizontal, vertical y oblicua. Su longitud también es muy variable: de 0,8 a $15 \mathrm{~cm}$, y se distribuyen por toda la superficie en algo más de un metro de ancho y $70 \mathrm{~cm}$ de altura. Su estado de conservación es deficiente debido a la alteración del soporte y a los desconchados de la capa superficial, que afectan a la totalidad e integridad de los grabados.

\section{LA DATACIÓN DEL GRAFISMO RUPESTRE DE EL MIRÓN: DISPOSITIVO ICONOGRÁFICO, ESTRATIGRAFÍA Y OCUPACIÓN HUMANA}

Las consideraciones a partir de los datos obtenidos en la excavación de los depósitos arqueológicos ayudan a proponer una cronología relativa del momento de ejecución de algunas grafías basada en datos radiométricos. Para el encuadre cronológico del conjunto 1 y de las unidades gráficas 1 y 2 se valora la diferencia de cota entre el panel y los niveles arqueológicos. Para ello se parte de tres factores:

1. Secuencia estratigráfica de referencia: las catas de furtivos y la posterior extracción de tierra para su uso como abono han alterado la se- cuencia estratigráfica prehistórica. Debajo de los grabados (cuadros W11-X12) ésta sólo se conserva a partir del nivel 120. Como secuencia de referencia más cercana se adopta un corte estratigráfico situado $210 \mathrm{~cm}$ al O y $100 \mathrm{~cm}$ al S, en los cuadros T10 y U10. Allí la secuencia se inicia con el nivel 105, a unos $100 \mathrm{~cm}$ por debajo del punto medio del conjunto $1 \mathrm{y}$ termina, según los trabajos realizados hasta el momento, con el nivel 116. El punto más bajo de la excavación está a unos $190 \mathrm{~cm}$ del punto medio del conjunto gráfico 1.

Antes de poner en relación la diferencia de cota existente entre el panel de grabados, donde se integran la unidad 1 y 2 y el conjunto 1 , y la última secuencia estratigráfica apuntada, debe explicarse la pertinencia del uso de dicho corte. Ello exige comprender la geometría de los niveles arqueológicos en el sector del 'Corral' tomando de referencia los cortes X8-W8, V7-V8, T7-U7V7, T7-T8-T9-T10 y T10-U10 (Fig. 9). La lectura de la estratigrafía muestra en el corte X8-W8 una ligera pendiente descendente hacia el $\mathrm{O}$. El corte V7-V8 tiende a la horizontalidad, carácter que se hace más acusado a partir del nivel 108. El corte T7-U7-V7 tiene una ligera pendiente descendente hacia el O. Situación similar se produce en el corte T7-T8-T9-T10, donde la pen-

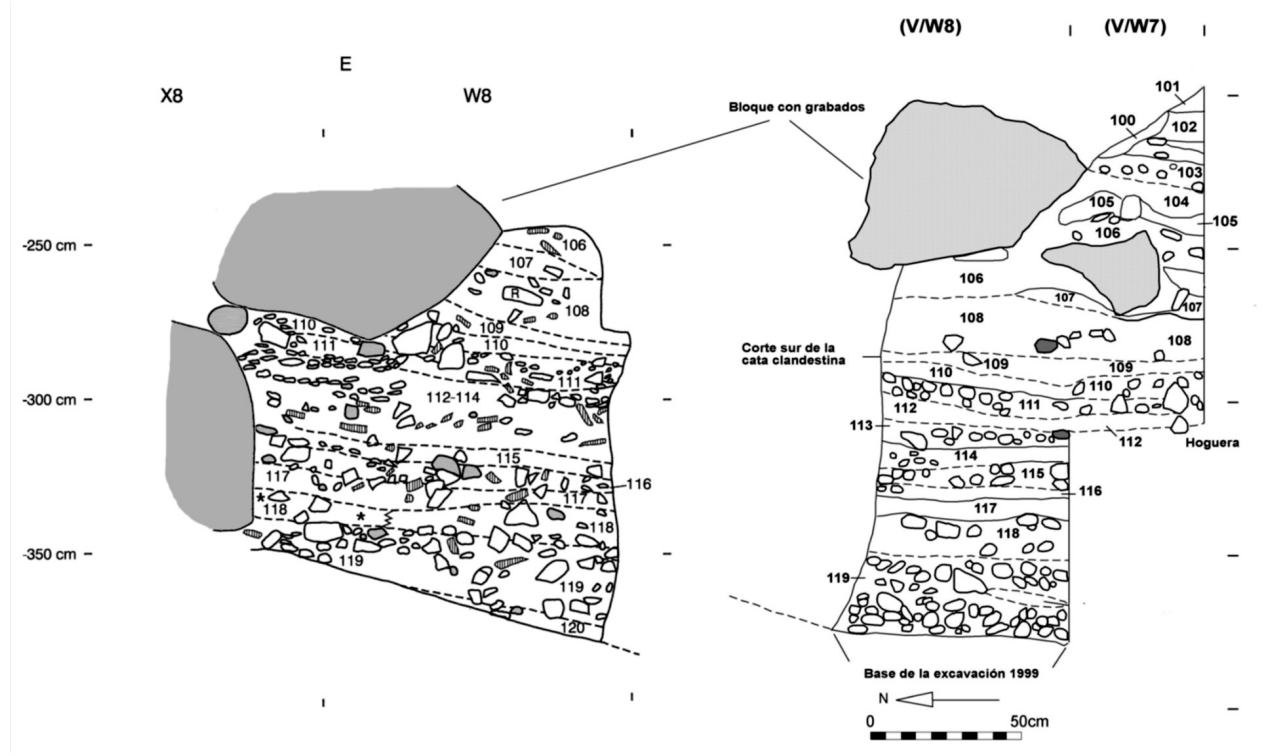

Fig. 9. Cortes estratigráficos norte (W8/X8) y oeste (V-W8/V-W7) del área del 'Corral' de El Mirón (Ramales de la Victoria, Cantabria), mostrando la ubicación estratigráfica del gran bloque desprendido. En el corte norte (a la izquierda de la imagen) se aprecia cómo la arista inferior del bloque se encaja en el nivel 110 (diagrama a partir de dibujos de los cortes de L. Straus y R. Stauber). 
diente, ligeramente más marcada y también descendente, buza hacia el N. En el corte T10-U10 los niveles en el cuadro T10 tienden a la horizontalidad, y en el cuadro U10 descienden en marcada pendiente hacia el O. Por su cercanía, los datos que puedan extrapolarse de la lectura del corte T10-U10 y de la complementariedad de los cortes T7-U7-V7 y T10-U10, ayudarán a comprender la relación entre los grabados y la secuencia estratigráfica:

a) El aumento de pendiente hacia el $\mathrm{O}$ es más acusado en el corte N (T10-U10) que en el S (T7-U7-V7) y se produce de manera progresiva.

b) Los niveles lito-arqueológicos del corte T10-U10 presentarían hacia el interior de la cueva una cota algo más alta. Si se extrapola el grado de pendiente del techo del nivel 107.2 y 108 al punto donde se sitúa el caballo (cuadro X12), se observa que la parte superior de la capa 107.2 estaría a unos $30-35 \mathrm{~cm}$ por debajo del mismo, y el techo del nivel 108 a unos 55-65 $\mathrm{cm}$. La base excavada del conjunto 108-112 se sitúa a una cota de $80-90 \mathrm{~cm}$.

Tales datos deben entenderse como valores extremos de distancia mínima, ya que la pendiente de los niveles 106 a 112 tendería a reducirse según se observa en los cortes X8-W8 y T7-U7V7. Si por contra consideramos valores extremos de distancia máxima (partiendo de una tendencia marcada a la horizontalidad de los niveles a partir del borde donde termina el corte de referencia en el cuadro U10), la distancia entre suelo y grafía zoomorfa es: 120-125 cm para la base del nivel $105,135-140 \mathrm{~cm}$ para la base del nivel 107 , $160-165 \mathrm{~cm}$ para la base del nivel 107.2 y $180-$ $185 \mathrm{~cm}$ para la base excavada del paquete 108112 (Fig. 10).

2. Inexistencia de fases erosivas entre niveles que pudieran desvirtuar las consideraciones sobre la altura del suelo: sobre la base de unas primeras apreciaciones de los procesos sedimentarios reconocidos en la cavidad (Straus et al. 2001) y de las dataciones obtenidas hasta el momento, puede afirmarse que al menos desde una fecha cercana a los $19.000 \mathrm{BP}$ y hasta los $8.000 \mathrm{BP}$ se ha producido una ocupación continuada y sin ruptura alguna de la secuencia que pudiera indicar la eliminación parcial o total de algunos niveles por fases erosivas.

3. Altura media del grabador: una persona entre $160-180 \mathrm{~cm}$ podría alcanzar hasta los $210-220$ $\mathrm{cm}$ si alzara la mano. El grabado inciso muy fino

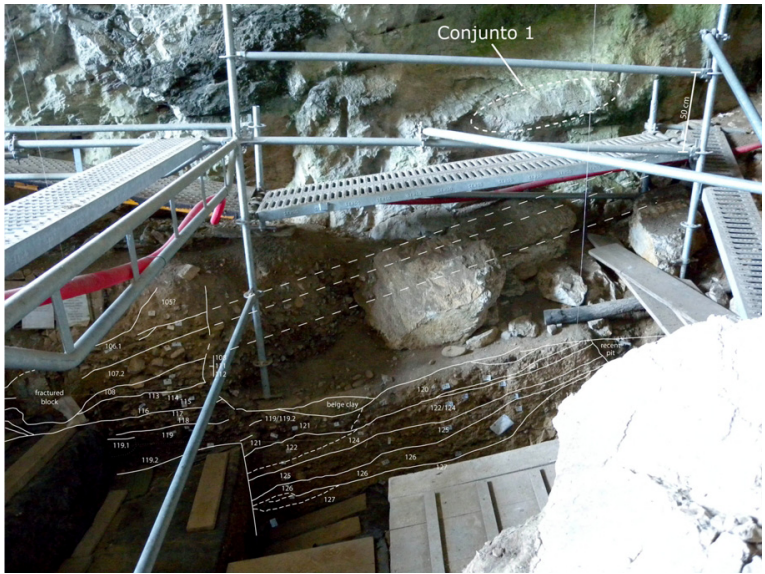

Fig. 10. El Mirón. Análisis gráfico del corte bajo el conjunto 1 , con la proyección teórica de la estratigrafía desaparecida y la ubicación de los grabados en la pared. A la derecha aparece la escala métrica (montaje de L. Teira).

de un motivo zoomorfo como el presentado exige que el autor en todo momento visualice correctamente el panel y lo que está grabando. La altura del soporte a grabar debe corresponderse con la distancia entre el suelo y el hombro (unos $25 \mathrm{~cm}$ por debajo de la cabeza). Por ello, se acepta el rango $135-155 \mathrm{~cm}$ como altura potencial máxima entre el plano donde se grababa y el suelo donde se situaba el artista. Partiendo de tales consideraciones, si los artistas no usaron estructuras para elevarse y grabaron de pie en una posición cómoda, la ejecución pudo corresponderse con la sedimentación del actual paquete 108-112, que contiene ocupaciones del Magdaleniense medio y del Magdaleniense inferior cantábrico. Este rango es el espectro temporal más probable de grabación para las unidades 1 y 2 y el conjunto 1 .

En cuanto a la estratigrafía parietal del bloque grabado: es otro elemento fundamental para la cronología relativa del conjunto gráfico 6 . El bloque se desprendió en un momento sincrónico a la formación del nivel 110, ya que en el corte $\mathrm{E}$ de los cuadros X8-W8 (Fig. 9) apoya sobre él. Dicho nivel ha sido asignado al Magdaleniense inferior cantábrico y está datado en $16.130 \pm 250$ BP (GX-23396) y, sobre un hueso justo por debajo del bloque, $16.520 \pm 40$ BP (UGAMS10628). La parte originariamente interior del bloque presenta líneas grabadas en parte cubiertas por sedimentos del nivel 104, datado de manera relativa entre el lapso $11.950 \pm 70 \mathrm{BP}(\mathrm{GX}-$ 
23417) (nivel 102.1, Aziliense/Magdaleniense superior-final) $-14.850 \pm 60,14.710 \pm 160$ y $13.660 \pm 70$ BP (nivel 108, Magdaleniense medio). En la campaña de 2001 se excavó la parte del sedimento de los niveles 104 y 105 que fosilizaba el sector sur del bloque, localizando la serie de líneas grabadas formando un motivo complejo de la zona derecha de la superficie del bloque bajo el sedimento intacto. En 2007 se completó la excavación del sedimento sobre la parte baja del bloque, hallando nuevas líneas grabadas bajo el sedimento del nivel 105. Como la cara grabada se corresponde con el plano de fractura y, en buena lógica, el acto de grabar se produjo tras la caída del bloque, las líneas hubieron de trazarse en un momento posterior o sincrónico a la formación del nivel 110 (caída del bloque) y anterior al nivel 105 (recubrimiento de los grabados), cuya datación debe insertarse entre el lapso $11.950 \pm 70 \mathrm{BP}$ (nivel 102.1) y $13.660 \pm 70 \mathrm{BP}$ (datación más reciente del nivel 108).

\section{VALORACIÓN DEL GRAFISMO RUPESTRE DE EL MIRÓN}

La cueva de El Mirón es una cavidad de corto recorrido y desarrollo lineal con tres tramos diferenciados: el vestíbulo de techo alto y amplias dimensiones, la rampa, estrecha y con pendiente muy marcada, y el interior, un espacio ancho de techo bajo, sin iluminación natural pero perfectamente transitable. Las excavaciones arqueológicas han revelado una importante secuencia del Paleolítico Superior y postpaleolítico en el vestíbulo.

Según los trabajos realizados hasta la fecha, se eligió para la actividad gráfica la zona exterior de la cavidad, iluminada por el sol. A pesar de ello, la modalidad de grabado no permite una lectura precisa y definida de todas las grafías. Las de surco más ancho (conjuntos 5 y 6 ) son reconocibles y observables durante todo el día. En cambio, para el resto, la buena visualización con luz natural se ciñe, preferentemente, a las horas de la tarde, cuando por la orientación al Oeste de la boca, la luz llega incluso directamente a las paredes del fondo del vestíbulo. Sin luz sólo se distingue un conjunto de líneas sin ordenación aparente.

El dispositivo iconográfico se compone de 2 unidades y 6 conjuntos gráficos. Las unidades son un equino (unidad 1) y una estructura reticulada (unidad 2). Los conjuntos gráficos son líneas de disposición aparentemente desordenada que tienden, a veces, a asociarse en paralelo formando pequeños grupos. En el conjunto 3 el trazado lineal se adecua a superficies y formas naturales pudiendo representar una figura de bisonte. La mayor parte de los grabados se localizan en frentes de pared: los conjuntos 1 y 2 y unidades 1 y 2 a la izquierda, y los conjuntos 3 a 5 a la derecha. Se desmarca el conjunto 6, sobre un bloque caído de la misma. Una disposición vertical y superficies preferentemente lisas o levemente sinuosas predominan en los soportes.

El estudio de la distribución o dispersión de los grabados en la cavidad valora su conservación. En la actualidad las grafías están a 20-33 m de la entrada, en el tránsito entre el vestíbulo y la rampa (donde se sitúa propiamente el conjunto 2). Pudieron existir otras en puntos más exteriores que, por procesos de alteración del soporte especialmente reconocibles en los conjuntos 1,2 y 3 , y unidades 1 y 2, no han perdurado. La visibilidad también importa: la mayoría de los conjuntos aparecieron tras la limpieza detenida de la superficie de las paredes, algunas muy cubiertas de suciedad.

El caballo, hasta la fecha es la única representación figurativa, muestra nivelación tendente a vertical $\left(5^{\circ}-15^{\circ}\right)$ y orientación hacia el interior de la cavidad. No está completa, pero basándose en la correspondencia de la anatomía con los desconchados del soporte pudiera pensarse que, en su día, se grabaran, cuanto menos, todas las líneas del contorno, según hemos descrito. Las pocas medidas tomadas imposibilitan el estudio preciso de las proporciones, si bien cabe apuntar el tronco ancho y la marcada concavidad del vientre. Es una figura de formato pequeño. La morfología de las líneas está entre el carácter rígido en las zonas del pecho y la extremidad delantera, ambas configuradas mediante líneas rectas, y el modulado. El esquema morfosomático de la región del tronco es rectangular.

La representación lineal, angular y tendente a paralelo, configura una morfología reticulada. Completan el repertorio los conjuntos gráficos con líneas donde no ha sido posible discriminar formas complejas.

La técnica de grabado es siempre la incisión fina y superficial, también describible como de carácter filiforme. En el caballo se recurre al 
grabado múltiple para la delineación de las líneas de contorno y a un estriado abundante y paralelo para el interior.

La propuesta cronológica para el caballo de El Mirón, por la correspondencia entre los grabados y los depósitos arqueológicos, apunta a un lapso que va del Magdaleniense inferior al medio. Las líneas grabadas del conjunto gráfico 6 se realizaron entre el Magdaleniense inferior cantábrico y el Magdaleniense medio avanzado o el Magdaleniense superior. Ello abre la posibilidad de que las grafías puedan ser contemporáneas.

\section{EL GRAFISMO RUPESTRE DE EL MIRÓN EN LA SECUENCIA GRÁFICA PALEOLÍTICA DEL VALLE DEL ASÓN}

En el valle del Asón y la inmediata depresión cerrada de Matienzo se ha mencionado actividad gráfica rupestre supuestamente paleolítica en 27 estaciones (Fig. 11)(1). Un primer grupo con representaciones cuya cronología paleolítica no parece cuestionable incluye las cuevas de El Otero (González Sainz et al. 1985), Los Emboscados y El Patatal o Sotarraña (Balbín et al. 1986), Cobrantes (García Guinea 1968), Sotarriza (González Sainz y San Miguel 2001: 133-136), Venta Laperra (Gorrotxategui 2000; García Díez y Eguizábal 2008), El Rincón (Montes et al. 2005; González Sainz y Gárate 2006), Arco A, Arco B, Arco C, Pondra, Morro del Horidillo (González Sainz y San Miguel 2001), La Haza (García Díez y Eguizábal 2007), Covalanas (Moure et al. 1985; García Díez y Eguizábal 2003), El Mirón (González Morales y Straus 2000b), La Luz (García Díez y Eguizábal 2010) y La Cullalvera (González Sainz et al. 1997).

Un segundo grupo integra los conjuntos grabados o pintados cuya cronología o estilo paleolítico es difícil de probar: abrigos de San Carlos y del Perro (Moure y González Morales 1986), San Juan de Socueva (Serna y Valle 2000), Cofresnedo (Smith 2002), El Risco (Serna 2002a), La Covarona (Gómez Arozamena 1992: 284), La Chora (Serna 2002b), Los Moros (Muñoz 2002a),

(1) En el Alto Asón también en la cueva de El Becerral se han señalado representaciones de estilo paleolítico (Bernaldo de Quirós et al. 1987, 1988-1989). Recientemente se ha certificado la falsificación de este conjunto (García Díez y Eguizábal 2007-2008)

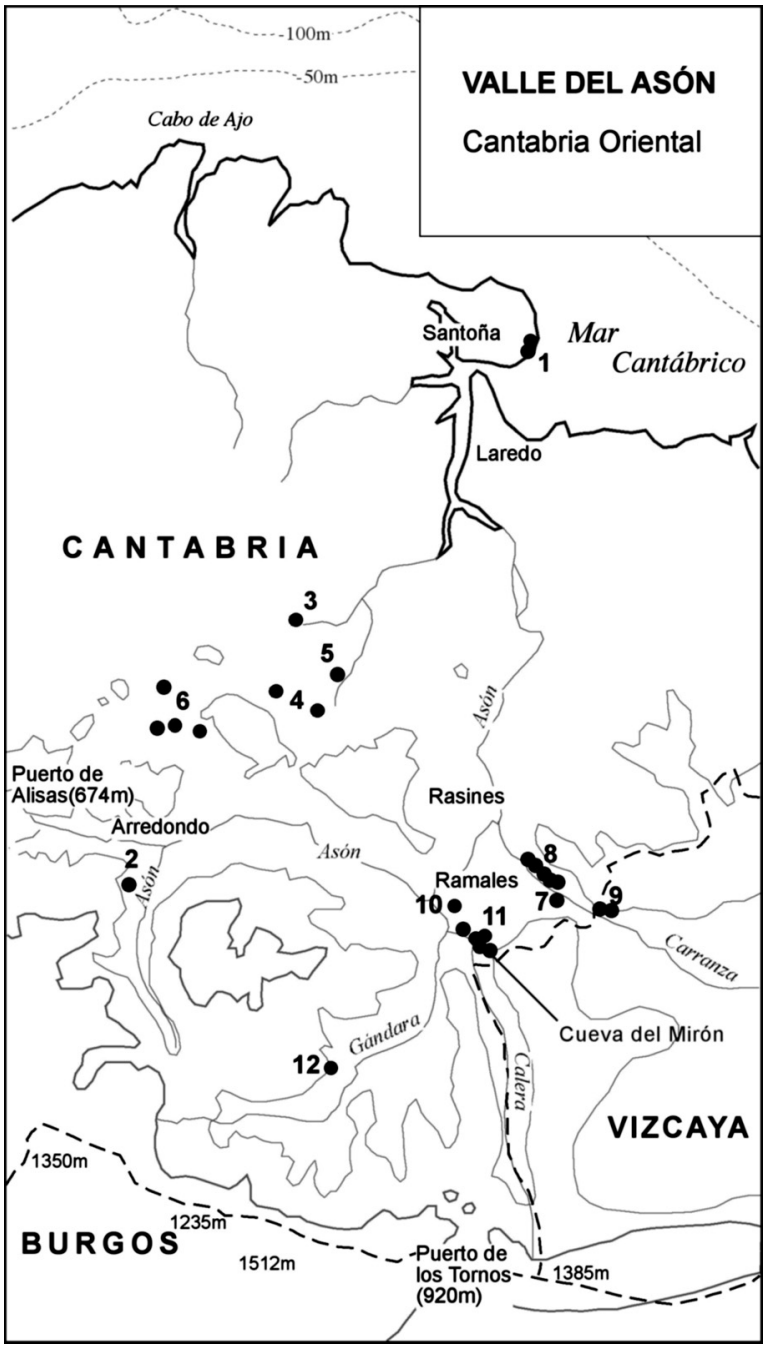

Fig. 11. Estaciones con arte parietal del valle del Asón (Cantabria) citadas en el texto. 1: San Carlos, El Perro; 2: San Juan de Socueva; 3: El Otero; 4: Cobrantes, La Covarona; 5: La Chora; 6: Emboscados, El Patatal, Cofresnedo, El Risco; 7: La Sotarriza; 8: El Morro del Horidillo, El Arco A, B y C; 9: Venta de la Perra, El Polvorín, El Rincón; 10: La Cullalvera; 11: La Haza, El Mirón, Covalanas, El Horno, La Luz; 12: Los Moros.

El Polvorín (Gárate 2008) y El Horno (Serna 2002c). La primera dificultad es la interpretación del origen, naturaleza y forma de las concentraciones de color en Cofresnedo, La Chora, Los Moros y El Horno. La segunda es la sencillez de las representaciones (puntos o líneas) cuya asignación, a priori y sin una discusión contextualizada, es insegura: San Carlos, San Juan de Socueva, Cofresnedo y El Polvorín. Los grabados del Abrigo del Perro son menos dudosos: un mo- 
tivo bastante complejo, con triángulos y series de ángulos, inmediatos a un depósito magdaleniense bien contrastado y cuyo paralelo formal más próximo es precisamente el nuevo motivo del bloque de El Mirón. Por último en El Risco y La Covarona la descripción hoy conocida consiste en escuetas notas insuficientes para la datación.

El conjunto de 17 estaciones con figuras seguras de cronología paleolítica nos acerca a la secuencia gráfica documentada en el valle del Asón. Sin pretender una discusión individualizada de su cronología, a partir de los datos hoy disponibles (González Sainz y San Miguel 2001)(2), se trazará su secuencia, valorando el grafismo de El Mirón en ese contexto.

Los primeros momentos de la actividad gráfica corresponden al ciclo pre-magdaleniense: motivos de Arco A, Arco B, Arco C, Pondra, Morro del Horidillo, Covalanas, La Haza, Venta de la Perra, El Risco y probablemente La Luz. Precisar la fecha concreta de su ejecución es problemático, siendo necesario recurrir a propuestas temporales de carácter amplio. Entre el Auriñaciense y el Solutrense inferior se realizaron los dispositivos iconográficos de Covalanas, La Haza, Morro del Horidillo, Arco C y una parte de los conjuntos de Pondra, Arco A y Arco B (todos los dibujos rojos). Entre el Gravetiense final y el Solutrense medio se grabaron las figuras de Venta de la Perra, La Luz y Arco B. En un lapso temporal algo más amplio (entre el Gravetiense final y el Solutrense final) se pintaron las ciervas de Pondra y los bisontes de Arco B, grabándose las figuras de Pondra y Arco A.

La propuesta cronológica para el ciclo magdaleniense puede precisarse más. Al Magdaleniense inferior se han adscrito las figuras de Emboscados y Cobrantes, las de esta última cavidad sin unanimidad entre los investigadores; algunos las asignan a momentos algo posteriores (Magdaleniense medio o superior). El dispositivo iconográfico de La Cullalvera se ha datado estilísticamente en el Magdaleniense medio avanzado. Durante el Magdaleniense superior-final se hicieron las figuras de Sotarriza y Otero. La cronología de la de El Patatal es difícil de precisar más allá de su pertenencia al presente ciclo.

(2) García Díez, M. 2002: Comportamiento gráfico durante el Paleolítico superior en el Alto Asón: análisis de los dispositivos iconográficos rupestres. Tesis doctoral. Departamento de Estudios Clásicos, Facultad de Filología, Geografía e Historia, Universidad del País Vasco.
La figura de equino de El Mirón, y probablemente la forma reticulada y por extensión, y cuando menos, otras líneas del conjunto gráfico 1, según la correspondencia entre proceso gráfico y depósitos arqueológicos, se realizaron entre el Magdaleniense inferior y el Magdaleniense medio. La concepción en parte geométrica del animal, en contraposición a lo definible como analítico 'puro', las proporciones un tanto abultadas en la región del vientre y el recurso al contorno múltiple llevan a vincular a la figura, a partir de un razonamiento formal de carácter lineal, al final del Magdaleniense inferior o inicio del Magdaleniense medio. Caracteres similares pueden reconocerse en Emboscados y Cobrantes.

Las líneas del conjunto gráfico 6 se ejecutaron entre el Magdaleniense inferior y el Magdaleniense medio avanzado o el Magdaleniense superior. El parecido más directo de los conjuntos del Alto Asón, cuya edad paleolítica está asegurada, es uno de los paneles de Venta de la Perra, compuesto exclusivamente de formas lineales. $\mathrm{Su}$ cronología es sensiblemente anterior, pero también hay referentes en otros de edad paleolítica insegura pero supuesta como los abrigos de San Carlos y sobre todo El Perro.

\section{AGRADECIMIENTOS}

Las investigaciones en la Cueva de El Mirón vienen siendo financiadas por la Fundación Marcelino Botín, la L. S. B. Leakey Foundation, la National Geographic Society, la National Science Foundation, la University of New Mexico, la Consejería de Educación, Cultura y Deporte del Gobierno de Cantabria y el Ministerio de Educación y Cultura. Los trabajos han contado con el apoyo de la Universidad de Cantabria, el Instituto Internacional de Investigaciones Prehistóricas de Cantabria y el Ayuntamiento de Ramales de la Victoria, y, por supuesto, con la constante ayuda y colaboración de Joaquín Eguizábal, guía de la cueva de Covalanas.

\section{BIBLIOGRAFÍA}

Alcalde del Río, H. 1906: Las pinturas y grabados de las cavernas prehistóricas de la Provincia de Santander. Altamira, Covalanas, Hornos de la Peña y El Castillo. Blanchard y Arce. Santander. 
Alcalde del Río, H.; Breuil, H. y Sierra, L. 1911: Les cavernes de la Région Cantabrique (Espagne). A. Chéne. Mónaco.

Balbín, R. de; González Morales, M. R. y González Sainz, C. 1986: "Los grabados y pinturas de las cuevas de Los Emboscados y El Patatal (Matienzo, Cantabria)". En Estudio de Arte Paleolítico, 15: 235-270. Centro de Investigación y Museo de Altamira. Madrid.

Bernaldo de Quirós, B.; Bohigas, R. y Cabrera, V. 1987: "Las pinturas rupestres de la cueva de Los Santos o del Becerral (La Gándara, Soba, Cantabria)". Boletín Cántabro de Espeleología 8: 133-140.

Bernaldo de Quirós, B.; Bohigas, R. y Cabrera, V. 1988-1989: "Las pinturas rupestres de la cueva de Los Santos o del Becerral (Cantabria)". Ars Praehistorica VII-VIII: 87-96.

Cabré, J. 1915: El arte rupestre en España. Memoria 1 , Comisión de Investigaciones Paleontológicas y Prehistóricas, Junta para Ampliación de Estudios e Investigaciones Científicas, Instituto Nacional de Ciencias Físico-Naturales, Museo Nacional de Ciencias Naturales. Madrid.

García Díez, M. y Eguizábal, J. 2003: La Cueva de Covalanas. El grafismo rupestre y la definición de territorios gráficos en el paleolítico cantábrico. Consejería de Cultura, Turismo y Deporte, Gobierno de Cantabria. Santander.

García Díez, M. y Eguizábal, J. 2007: “Los dibujos rojos de estilo paleolítico de la Cueva de la Haza (Ramales de la Victoria, Cantabria)". Munibe 58: 177-222.

García Díez, M. y Eguizábal, J. 2007-2008: “¿Del estilo paleolítico a la cronología contemporánea?: una nueva versión del arte parietal de la cueva de el Becerral (La Gándara, Cantabria)". Veleia 24-25: 285-304.

García Díez, M. y Eguizábal, J. 2008: La Cueva de Venta Laperra. El grafismo parietal paleolítico y la definición de territorios gráficos en la región cantábrica. Karrantza Harana. Carranza.

García Díez, M. y Eguizábal, J. 2010: “La luz”. En B. Malpelo e I. Castanedo (coords.): Las Cuevas con Arte Paleolítico en Cantabria. Asociación Cántabra para la Defensa del Patrimonio Subterráneo. Santander: 309-310.

García Guinea, M. A. 1968: Los grabados de la cueva de La Peña del Cuco en Castro Urdiales y de la cueva de Cobrantes (Valle de Aras). Diputación de Santander. Santander.

Gómez Arozamena, J.; Muñoz, E.; Rodríguez, T. y Smith, P. 1992: "Las cuevas con arte esquemático en Cantabria". Actas del V Congreso Español de Espeleología (Camargo, Santander 1990): 279290. Santander.

González Echegaray, J. y González Sainz, C. 1994: "Conjuntos rupestres paleolíticos de la Cornisa Cantábrica”. Complutum 5: 21-43.
González Morales, M. y Straus, L. G. 1997: “La Prehistoria del Valle del Asón: Excavaciones en la Cueva de El Mirón. La campaña de 1996". II Congreso de Arqueología Peninsular (Zamora 1996). Paleolítico y Epipaleolítico I: 119-131. Zamora.

González Morales, M. y Straus, L. G. 2000a: “La cueva de El Mirón (Ramales de la Victoria, Cantabria): excavaciones 1996-1999". Trabajos de Prehistoria 57 (1): 121-133.

González Morales, M. y Straus, L. G. 2000b: "Parietal engravings in magdalenian stratigraphic context in El Mirón Cave (Ramales de la Victoria, Cantabria, Spain)". International Newsletter on Rock Art 27: $1-5$.

González Morales, M. y Straus, L. G. 2000c: "El depósito arqueológico de la prehistoria reciente de la Cueva de El Mirón (Ramales, Cantabria): bases estratigráficas para una secuencia regional". Actas do 3. ${ }^{\circ}$ Congresso de Arqueologia Peninsular (Vila Real, 1999) Paleolítico da Península Ibérica IV: 49-63. Porto.

González Morales, M. y Straus, L. G. 2005: "The Magdalenian sequence of El Mirón Cave (Cantabria, Spain): an approach to the problems of definition of the Lower Magdalenian in Cantabrian Spain". En V. Dujardin (ed.): Industrie osseuse et parures du Solutréen au Magdalénien en Europe. Société Préhistorique Française. París: 209-219.

González Morales, M.; Straus, L. G. y Marín, A. B. 2006: "Los omóplatos decorados magdalenienses de la Cueva de El Mirón (Ramales de la Victoria, Cantabria) y su relación con la Cueva del Castillo". En J. M. Maíllo y E. Baquedano (eds.): Miscelánea en homenaje a Victoria Cabrera. Zona Arqueológica 7, Museo Arqueológico Regional. Madrid: 483-494.

González Sainz, C. y Gárate, D. 2006: “Los grabados y pinturas de la Cueva de El Rincón, en el contexto artístico del desfiladero del río Carranza (BizkaiaCantabria)". Zephyrvs 59: 285-304.

González Sainz, C.; Muñoz, E. y Morlote, J. M. 1997: "De nuevo en La Cullalvera (Ramales, Cantabria). Una revisión de su conjunto rupestre paleolítico". Veleia 14: 73-100.

González Sainz, C.; Muñoz, E. y San Miguel, C. 1985: "Los grabados rupestres paleolíticos de la cueva del Otero (Secadura - Cantabria)". Sautuola 4: $155-164$.

González Sainz, C. y San Miguel, C. 2001: Las cuevas del desfiladero. Arte rupestre paleolítico en el valle del río Carranza (Cantabria-Vizcaya). Gobierno de Cantabria y Universidad de Cantabria. Santander.

Gorrotxategi, X. 2000: Arte paleolítico parietal de Bizkaia. Kobie, anejo 2. Diputación Foral de Bizkaia. Bilbao.

Moure, A. y González Morales, M. R. 1986: "Los grabados de los abrigos de El Perro y San Carlos (Santoña, Cantabria)". Estudios en Homenaje al 
Dr. A. Beltrán Martínez. Universidad de Zaragoza. Zaragoza: 103-114.

Muñoz, E. 2002a: "Los Moros". En M. L. Serna, A. Valle y P. Smith (coords.): Las cuevas con arte paleolítico en Cantabria. Asociación Cántabra para la Defensa del Patrimonio Subterráneo. Santander: 325.

Muñoz, E. 2002b: "La Luz". En M. L. Serna, A. Valle y P. Smith (coords.): Las cuevas con arte paleolitico en Cantabria. Asociación Cántabra para la Defensa del Patrimonio Subterráneo. Santander: 325.

Obermaier, H. 1916: El Hombre Fósil. Memoria 9 de la Comisión de Investigaciones Paleontológicas y Prehistóricas, Junta para Ampliación de Estudios e Investigaciones Científicas, Museo Nacional de Ciencias Naturales. Madrid.

Serna, M. L. 2002a: "El Risco". En M. L. Serna, A. Valle y P. Smith (coords.): Las cuevas con arte paleolitico en Cantabria. Asociación Cántabra para la Defensa del Patrimonio Subterráneo. Santander: 324.

Serna, M. L. 2002b: "La Chora". En M. L. Serna, A. Va1le, P. Smith (coords.): Las cuevas con arte paleolitico en Cantabria. Asociación Cántabra para la Defensa del Patrimonio Subterráneo. Santander: 325.

Serna, M. L. 2002c: "El Horno o el Llano". En M. L. Serna, A. Valle y P. Smith (coords.): Las cuevas con arte paleolítico en Cantabria. Asociación Cántabra para la Defensa del Patrimonio Subterráneo. Santander: 326.

Serna, M. L. y Valle, A. 2000: "El conjunto de pinturas rojas del abrigo de San Juan de Socueva (Socueva, Arredondo)". Boletín Cántabro de Espeleología 14: 129-138.

Sierra, L. 1909: "Notas para el mapa paletnográfico de la Provincia de Santander". Actas y memorias del Primer Congreso de Naturalistas Españoles (Zaragoza 1908): 103-117. Zaragoza.

Smith, P. 2002: "Cofresnedo". En M. L. Serna, A. Valle y P. Smith (coords.): Las cuevas con arte paleolitico en Cantabria. Asociación Cántabra para la Defensa del Patrimonio Subterráneo. Santander: 237-240.

Straus, L. G. y González Morales, M. 1996: "Preliminary excavations in El Mirón cave (Ramales de la Victoria, Cantabria, Spain)". Old World Archaeology Newsletter 20-1: 14-18.

Straus, L. G. y González Morales, M. 1997: “The Río Asón Prehistoric Project: 1997 Excavations in El Mirón Cave (Ramales de la Victoria, Cantabria, Spain)". Old World Archaeology Newsletter 21-1: 14-18.

Straus, L. G. y González Morales, M. 1998: "Report on the initial excavations in El Mirón cave (Ramales de la Victoria, Cantabria, Spain) with emphasis on the Magdalenian occupations". Journal of Iberian Archaeology 0: 173-188.

Straus, L. G. y González Morales, M. 1998-99: “1998 excavation campaign in El Mirón cave (Ramales de la Victoria, Cantabria, Spain)". Old World Archaeology Newsletter 21-3: 1-9.
Straus, L. G. y González Morales, M. 1999-2000: "The fourth excavation campaign in El Mirón cave (Ramales de la Victoria, Cantabria, Spain)". Old World Archaeology Newsletter 22-2: 1-8.

Straus, L. G. y González Morales, M. 2000: "The Mirón cave/Asón river valley prehistoric project (Cantabria, Spain): the upper paleolithic components". 3. ${ }^{\circ}$ Congresso de Arqueologia Peninsular (Vila Real, 1999), Paleolítico da Península Ibérica II: 351-362. Porto.

Straus, L. G. y González Morales, M. 2001a: “El Mirón Cave 2001: Continuing excavations by the Universities of Cantabria and New Mexico". Old World Archaeology Newsletter 28-2: 1-5.

Straus, L. G. y González Morales, M. 2001b: "The Upper Paleolithic in El Mirón Cave (Ramales, Cantabria, Spain)". En P. Noiret (ed.): Le Paléolithique Supérieur Européen: Bilan Quinquennal 1996-2001. Université de Liège. Liège: 135-139.

Straus, L. G. y González Morales, M. 2003a: "Early-Mid Magdalenian excavations in El Mirón Cave (Ramales, Cantabria, Spain). Report on the VII Campaign (2002)". Eurasian Prehistory 1: 117-137.

Straus, L. G. y González Morales, M. 2003b: "El Mirón cave \& the radiocarbon chronology of Cantabrian Spain". Radiocarbon 45-1: 41-58.

Straus, L. G. y González Morales, M. 2003c: "A Spanish time tunnel: El Mirón Cave". Athena Review 3 (3): 67-74.

Straus, L. G. y González Morales, M. 2005: "El Magdaleniense de la Cueva de El Mirón (Ramales de la Victoria, Cantabria, España): observaciones preliminares". En N. Ferreira Bicho (ed.): O Paleolítico. Actas do IV Congresso de Arqueologia Peninsular (Faro, 2004): 49-62. Faro.

Straus, L. G. y González Morales, M. 2008: "Further radiocarbon dates for the Upper Paleolithic of El Mirón Cave (Ramales de la Victoria, Cantabria, Spain)." Radiocarbon 49, 3: 1205-1214.

Straus, L. G. y González Morales, M. 2010: "The radiocarbon chronology of El Mirón Cave (Cantabria, Spain): new dates for the initial magdalenian occupations". Radiocarbon 52, 1: 33-39.

Straus, L. G.; González Morales, M.; García Gelabert, M. P. y Fano, M. 2002a: "The Late Quaternary human uses of a natural territory: the case of the Río Asón drainage (eastern Cantabria province, Spain)". Journal of Iberian Archeology 4: 21-61.

Straus, L. G.; González Morales, M.; Fano, M. y García Gelabert, M. P. 2002b: "Last Glacial human settlement in eastern Cantabria". Journal of Archaeological Science 29: 1403-1414.

Straus, L. G.; González Morales, M.; Farrand, W. y Hubbard, W. 2001: "Sedimentological and stratigraphic observations in El Mirón, a late Quaternary cave site in the Cantabrian Cordillera, northern Spain". Geoarchaeology 16: 603-630. 